\title{
Immediate Outcome of Vlbw And Elbw Babies in a Tertiary Care Center of Nepal
}

\author{
Acharya $\mathrm{N}^{1}$, Mishra $\mathrm{P}^{2}$, Shrestha $\mathrm{N}^{3}$, Gupta $\mathrm{V}^{4}$
}

\begin{abstract}
Background: Very Low Birth Weight (VLBW) infants weigh $<1500$ grams and Extremely Low Birth Weight (ELBW) infants weigh $<1000$ grams. They are predominantly premature but may also be associated with Intrauterine Growth Restriction (IUGR). The VLBW rate is an accurate predictor of infant mortality rate. Objective: The study was aimed to find out the hospital incidence of VLBW and ELBW babies and outcome of these babies, till they were discharged from the hospital/NICU. Methods: A descriptive study was conducted among 109 cases who weighed less than 1500 grams. The babies were evaluated for mortality and various morbidities till they were discharged from the hospital. Descriptive statistics was applied using SPSS 21.0 to show antenatal profile and immediate outcome. Results: Out of 109 cases, ELBW were $30.2 \%$ and VLBW were $69.8 \%$. Among the ELBW babies, $30.3 \%$ survived and $75 \%$ in VLBW. The mortality rate in ELBW and VLBW babies were $69.7 \%$ and $25 \%$ respectively. Among the ELBW, common morbidities were NNJ (94\%), Presumed NNS (87.8\%), RDS (82.6\%), Hypoglycemia (56.5\%), Hypothermia (26\%), Birth Asphyxia (15.1\%). In the VLBW group, common morbidities were Presumed NNS (86.4\%), NNJ (82\%), RDS (46.5\%), Hypoglycemia (30.2\%). The mean duration of hospital stay was 8.6 days ( $S D \pm 3.38$ ). Conclusions: Common immediate morbidities were NNS, RDS, Hypothermia, Anemia, Shock, CHD, Birth Asphyxia and NEC. Well trained staff in the NICU and medical facilities like availability of Surfactant therapy, more number of mechanical ventilators could improve the survival of these babies in our setting.
\end{abstract}

Key words: Extremely low birth weight, morbidity, mortality, very low birth weight

\section{INTRODUCTION}

In every community mothers and children are among the groups that are vulnerable to disease, disability and death. Their vulnerability is a result of possession of the special characteristics of pregnancy or young age, related to biological process of reproduction, growth and development ${ }^{1}$. Birth weight is the single most important marker of adverse perinatal and neonatal outcome ${ }^{2}$. It has been reported that over $60-$ $80 \%$ of all neonatal mortality and morbidity is due to preterm birth $^{3}$. VLBW infants weigh $<1500 \mathrm{~g}$ and are predominantly premature but may also be associated with IUGR. The VLBW rate is an accurate predictor of IMR. Perinatal care has improved the rate of survival of VLBW infants. When compared to term infants, VLBW neonates have a higher incidence of rehospitalization during the $1^{\text {st }}$ year of life for sequelae of prematurity, infections, neurologic complications and psychosocial disorders ${ }^{4}$. The commoner neonatal complications in both VLBW and ELBW babies were RDS, neonatal jaundice and sepsis ${ }^{10}$. With the introduction of modern methods of neonatal intensive care there occurred a

1. Dr. Niraj Acharya

2. Dr. Pradeep Mishra

3. Dr. N. Shrestha

4. Prof. Veena Gupta

Address for correspondence:

Dr. Niraj Acharya

Department of Pediatrics

Nepalgunj Medical College Teaching Hospital

Kohalpur, Banke, Nepal

E-mail: drnirajacharya@hotmail.com significant improvement in the outcome of VLBW \& ELBW babies, but still it remains as one of the important causes of neonatal mortality in developing countries ${ }^{5}$. These babies need to spend time in NICU till close to term to allow multi organ development. So, the consequences of preterm birth often continue beyond the neonatal period and can lead to significant direct and indirect costs that have to be borne by the parents and the society ${ }^{6}$. Here we present this descriptive study of immediate neonatal outcome of very low birth weight $(<1500 \mathrm{gm})$ and extremely low birth weight $(<1000 \mathrm{gm})$ babies.

\section{METHODS:}

This descriptive study was conducted in our department of Pediatrics, Nepalgunj Medical College, Kohalpur for a period of one year from January 2013 to January 2014. This centre caters to mainly pregnant mothers from mid and far west region of Nepal. Those neonates fulfilling inclusive criteria and weighing less than 1500 grams were enrolled in our study. The convenience non probability sampling technique was undertaken and the minimum required sample size was calculated using formula $n=z 2 p q / d 2$. Thus the calculated sample size was, $n=109$ after adjusting $5 \%$ non response. Data collection was done by reviewing book of mother and the neonatal profile of VLBW $(<1500 \mathrm{gm})$ and ELBW $(<1000 \mathrm{gm})$ babies like gestational age, asphyxia requiring ventilator support, Hyaline membrane disease, presume sepsis, jaundice, Hypoglycemia, Hypothermia, stay in NICU and total hospital stay were recorded. All data were entered in SPSS version 21 and descriptive statistics was used for analysis of data.

RESULT:

A total number of 109 VLBW and ELBW babies were included 
this study. Seventy five (70.7\%) mothers were booked and thirty one (29.3\%) was unbooked. In our study, out of 106 pregnant mothers, 68 (64.2) were primigravida and 38 (35.8\%) were mutligravida. The age of the mothers ranged from 15 to 36 years with a mean of 26.2 years. There were 48 (45.3\%) mothers who delivered vaginally and $58(54.7 \%)$ mothers were undergone for cesarean section with the most common indication was prolonged labor. out of 106 mothers, three (2.8\%) mothers gave twin delivery and rest were singleton. Among the total 109 babies, $33(30.2 \%)$ were ELBW whereas 76 $(69.7 \%)$ were VLBW. The mean gestational age of VLBW group and ELBW group was $30 \pm 1.72$ and $28.93 \pm 1.39$ respectively. Similarly, the mean weight of VLBW group and ELBW group was $1288.42 \pm 138.95$ and $894.84 \pm 71.50$ respectively. The overall mortality in ELBW group was $69.7 \%$ and in VLBW group was $25 \%$ only. All babies who survived in both group were admitted in NICU for supporting treatment.

\begin{tabular}{|c|c|c|c|}
\hline $\begin{array}{c}\text { Gestational } \\
\text { Period }\end{array}$ & $\begin{array}{c}\text { No. of babies } \\
\text { Delivered }\end{array}$ & $\begin{array}{c}\text { No. of babies } \\
\text { Survived }\end{array}$ & Mortality \\
\hline$\leq 28$ & 7 & $1(14.3 \%)$ & $6 / 7(85.7 \%)$ \\
\hline 29 to 32 & 72 & $40(55.6 \%)$ & $32 / 72(44.4 \%)$ \\
\hline$>32$ & 30 & $26(86.6 \%)$ & $4 / 30(13.4 \%)$ \\
\hline \multicolumn{4}{|c|}{ Birth Weight (gm) } \\
\hline$<800$ & 10 & $0(0 \%)$ & $10 / 10(100 \%)$ \\
\hline 801 to 1000 & 23 & $10(43.5 \%)$ & $13 / 23(56.5 \%)$ \\
\hline 1001 to 1250 & 30 & $20(66.7 \%)$ & $10 / 30(33.3 \%)$ \\
\hline 1251 to 1500 & 46 & $37(79.5 \%)$ & $9 / 46(19.5 \%)$ \\
\hline
\end{tabular}

No. of VLBW - 76

No. of ELBW - 33

Table I: Number of Deliveries in Each Weight and Gestational Age Groups and Corresponding Mortality

The various conditions recorded in our case sheets of both ELBW and VLBW neonates till discharge is given in table II. The common complications seen in both the groups were neonatal jaundice $(93.9 \%$ in ELBW and $81.5 \%$ in VLBW babies) and presume neonatal sepsis (87.8\% in ELBW and $86.8 \%$ in VLBW babies) whereas RDS (57.5\% in ELBW and 52\% in VLBW babies). The incidence of RDS was found to be lower (4 out of 28) where 2 doses of betamethasone could be given. The other common complications found in both the groups were hypoglycemia, hypothermia and birth asphyxia. The duration of hospital stay in both groups were ranged from $3-20$ days. The mean duration of stay in NICU was 8.16 days (SD \pm 3.38 ) in both groups of babies.

\begin{tabular}{|l|c|c|}
\hline Outcomes & ELBW (\%) & VLBW (\%) \\
\hline NNJ & $31(93.9)$ & $62(81.5$ \\
\hline NNS & $29(87.8)$ & $66(86.8)$ \\
\hline Hypoglycemia & $13(39.3)$ & $26(34.2)$ \\
\hline Hypothermia & $6(18.1)$ & $19(25)$ \\
\hline CHD & $1(3)$ & $3(3.9)$ \\
\hline RDS & $19(57.5)$ & $40(52)$ \\
\hline Birth Asphyxia & $5(15.5)$ & $7(9.2)$ \\
\hline Shock & $1(3)$ & $4(5.2)$ \\
\hline NEC & $1(3)$ & $1(1.3)$ \\
\hline Anemia & $2(6)$ & $5(6.5)$ \\
\hline Total & $33(100)$ & $76(100)$ \\
\hline
\end{tabular}

Table II: immediate outcome of ELBW and VLBW groups

\section{DISCUSSION}

Preterm deliveries of babies weighing less than 1500 gms (VLBW) and particularly less than 1000 gms (ELBW) are of major concern because of maximum perinatal morbidity and mortality found in this ${ }^{7,889}$. A total of 109 babies were included in the study, among which 33 (30.2\%) were ELBW and 76 (69.8\%) were VLBW. In our study, mean gestational age in ELBW and VLBW group was $30 \pm 1.72$ and $28.93 \pm 1.39$ respectively which is similar to study done in India. Among ELBW group, only 10 (30.3\%) survived and among VLBW, 57 survived $(75 \%)$. Our results are comparable to the results of Poudel et $\mathrm{al}^{7}$ where the survival rate of VLBW babies was $54.3 \%$. There is a wide variety of survival rate reported in various ${ }^{9,10 \& 13}$. Similarly, mortality rate among ELBW group was $69.7 \%$ and in VLBW was $25 \%$ but other studies showed lower percentage of mortality rate ${ }^{9,10}$. This is due to difference in patient population, antenatal care, intranatal care, aggressive neonatal care and availability of NICU facilities. The poor survival rate in our study could be due poor affordability of parents, unavailability of Surfactant therapy and the lack of proper NICU facilities (mechanical ventilator) at times.

Various neonatal outcomes were evaluated in our study. Among the ELBW babies, the most common complication was Neonatal Jaundice (94\%) followed by Neonatal Sepsis (87.8\%), RDS (82.6\%), Hypoglycemia (56.5\%), Hypothermia (26\%), Birth Asphyxia (15.1\%). In the VLBW group, the most common complication seen was presumed Neonatal Sepsis (86.4\%), followed by Neonatal Jaundice (82\%), RDS (46.5\%), Hypoglycemia (30.2\%), Hypothermia (19\%), Birth Asphyxia (9.2\%). Similarly in the study done by Poudel et al ${ }^{7}$, the most common morbidity in VLBW babies was Clinical Sepsis (77.1\%), followed by Neonatal Jaundice (73.6\%). RDS was seen in $21.4 \%$, which is lower than that found in our study (46.5\%). Other studies showed dissimilar finding than our ${ }^{9,10 \& 12}$. Dissimilarities in immediate neonatal outcome are mainly confined on antenatal cares, intrapartum monitoring, use of antenatal 
steroid and place of delivery. Most of the preterm newborns were referred cases in our NICU so they were deprived from proper care, antenatal. Diagnosis of Intraventricular Hemorrhage was excluded because the cranial ultrasound could not be done in all suspected cases due to the lack of adequate resources of the parents of the patients. In our study mean duration of hospital is similar to other studies done in India ${ }^{9,10}$ and Nepal ${ }^{6}$.

\section{CONCLUSIONS}

The large percentages of ELBW babies were prematurely expired but two third VLBW babies were survived in our study. Neonatal Jaundice, presume sepsis, HMD and metabolic problems are major immediate outcome in both groups.

\section{REFERENCES}

1 World health organization. Risk approach for maternal and child health care. Geneva:WHO; 1978. p2-4.

2 Singh M. Care of the Newborn; $7^{\text {th }}$ ed, New Delhi: Sagar; 2010. p. 234- 54 .

3 Goldenberg RL. The management of preterm labor. Obstet Gynaecol 2002; 100(5):1020-34.

4. Carlo WA. Prematurity and Intrauterine Growth Restriction. In: Kliegman RM, Stanton BF, St. Geme JW, Schor NF, Behrman RE, editors. Nelson Textbook of Pediatrics. $19^{\text {th }}$ ed. Philadelphia: Elsevier; 2011. p. 555-64.

5. Brothwood M, Wolke D, Gamsu H, Cooper D. Mortality, morbidity, growth and development of babies weighing 5011000 grams and 1001-1500 grams at birth. Acta Paediatr Scand 1988;77(1):10-8.

6. Poudel P, Budhathoki S, Shrivastava MK. Maternal risk factors and morbidity pattern of very low birth weight infants: a NICU based study at eastern Nepal. J Nepal Pediatr Soc 2009;29(2):59-66.

7. Mansouri HA. Perinatal factors and neonatal outcome of very low birth weight and extremely premature babies at KAUH. Bahrain Med Bull 2001;23(2):1-10.

8. Kayastha S, Tuladhar H. Study of low birth weight babies in Nepal Medical College. Nepal Med Coll J 2007;9(4):266-9.

9. Roy KK, Baruah J, Kumar S, Malhotra N, Deorari AK, Sharma JB. Maternal Antenatal Profile and Immediate Neonatal Outcome in VLBW and ELBW Babies. Indian J Pediatr 2006; 73(8):669-73

10. Sehgal A, Telang S, Passah SM, Jyothi MC. Maternal and Neonatal Profile and Immediate Outcome in ELBW. Indian J Pediatr 2003;40(10):991-5.

11. Monirujjaman M, Azhar BS, Islam KS, Ferdouse A, Afrin S, Hossain MS. Maternal Obstetric and morbidity factors in relation to infant birth weight. Sch J App Sci 2014;2(2):539-47.

12. Dhankar $M$, Rawat $A K$, Varun. Etiological factors associated with low birth weight newborns. International Journal of Basic and Applied Medical Sciences 2013;3(3):44-8.

13. Shankaran S, Fanaroff AA Wright LL, Stevenson DL, Donovan FF, Ehrenkranz RA et al. Risk factors for early death among extremely low birth weight infants. Am J Obstet Gynaecol 2002;186(4):796802. 